\title{
Is it safe to use preprepared endotracheal tubes in the resuscitation room?
}

\author{
Anthony Bleetman, Neil Ashwood
}

\begin{abstract}
Objective-To investigate the bacteriological safety of preprepared endotracheal tubes in accident and emergency departments.

Methods-Swabs were taken and cultured from luminal and exterior surfaces of every preprepared exposed endotracheal tube in a hospital resuscitation room. Results-Coagulase negative staphylococci (common skin commensals) were isolated from $50 \%$ of the tubes. No other bacteria were isolated.

Conclusions-The practice of leaving preprepared airway equipment exposed in the resuscitation room is unlikely to contribute to the development of nosocomial pneumonia, provided the equipment is kept dry and that personnel minimise handling.

( F Accid Emerg Med 1996;13:283-284)
\end{abstract}

Key terms: emergency intubation; nosocomial infection; pneumonia; resuscitation room

Forty five per cent of patients who have undergone emergency endotracheal intubation develop nosocomial pneumonia. ${ }^{1}$

It is common practice for accident and emergency (A\&E) departments to have a selection of preprepared endotracheal tubes available for rapid intubation in each bay in the resuscitation room, either in trays or secured by clips to a wall board. This hospital's A\&E department has three patient bays in the resuscitation room. Each bay has its own set of preprepared endotracheal tubes and intubation equipment in a tray. The tubes are removed from their sterile packaging, cut to length, and the inflatable cuffs tested before placement in a tray in each bay. The tubes are replaced only after use.

Accident and

Emergency

Department,

Addenbrooke's NHS

Trust,

Hills Road,

Cambridge CB2 2QQ,

United Kingdom

A Bleetman

N Ashwood

Correspondence to:

Anthony Bleetman FRCSEd,

96 The Rowans,

Milton,

Cambridge CB4 6YU

Accepted for publication

24 January 1996

\section{Methods}

In order to determine if this exposure of preprepared airway equipment leads to the colonisation of endotracheal tubes with potentially harmful pathogens, every endotracheal tube (sizes $5-9.5 \mathrm{~mm}$ ) from each of the three resuscitation bays was swabbed in a standardised way with a sterile saline soaked swab from both the external surface and the lumen. Extreme care was taken to prevent contamination of the equipment and of the swabs by the investigators. The swabs were cultured for 72 hours and the number and type of colony forming units were recorded. In addition swabs were taken from the blade of the laryngoscope in each bay.

\section{Results}

Bacteria were cultured from $15(50 \%)$ of the 30 endotracheal tubes. All cultured bacteria were coagulase negative Staphylococcus epidermidis. Three endotracheal tubes in bay 1 , five in bay 2, and seven in bay 3 grew bacterial colony forming units. None of the laryngoscope blades grew bacteria.

Of the 15 contaminated tubes, nine $(60 \%)$ had bacteria on the external surface only, two $(13.3 \%)$ within the lumen only, and four $(26.7 \%)$ on both surfaces. The distribution of colony forming units is shown in the table.

No virulent pathogens were isolated from any of the airway equipment.

\section{Discussion}

The coagulase negative staphylococci that were cultured are likely to represent contamination from the skin of personnel using and checking the equipment on a daily basis. The higher incidence of colony forming units in bay 3 may represent a higher level of activity in this bay and subsequent increased handling and turnover of the airway equipment.

The prevalence of nosocomial pneumonia is high $(45 \%)$ in patients who have required

Number of colony forming units cultured from swabs of endotracheal tubes and larynoscope blades

\begin{tabular}{lllc}
\hline Equipment & Bay 1 & Bay 2 & Bay 3 \\
\hline Tube & & & \\
5 external & 1 & 1 & 30 \\
5 lumen & 0 & 0 & 0 \\
5.5 external & 0 & 0 & 0 \\
5.5 lumen & 0 & 0 & 0 \\
6 external & 0 & 0 & 0 \\
6 lumen & 0 & 0 & 0 \\
6.5 external & 0 & 0 & 2 \\
6.5 lumen & 0 & 0 & 0 \\
7 external & 0 & 0 & 0 \\
7 lumen & 0 & 0 & 0 \\
7.5 external & 0 & 3 & 4 \\
8 external & 0 & 0 & 1 \\
8 lumen & 0 & 1 & 11 \\
8.5 external & 0 & 0 & 7 \\
8.5 lumen & 1 & 0 & 0 \\
9 external & 0 & 0 & 0 \\
9 lumen & 0 & 1 & 3 \\
9.5 external & 3 & 1 & 0 \\
9.5 lumen & 0 & 1 & 88 \\
Laryngoscope blade & 0 & 0 & 0 \\
Total & 0 & 0 & 0 \\
\hline
\end{tabular}


emergency intubation. ${ }^{1}$ In particular, the rate of respiratory nosocomial infections is high in victims of multiple trauma admitted to intensive care units. ${ }^{2}$

The common causative pathogens tend to originate in the patient's oropharynx and stomach contents and proliferate in damp conditions. ${ }^{3-5}$ Bacteria from manual ventilation bags have been recognised as a source of colonisation of intubated patients. ${ }^{6}$ However, this department uses sterile disposable manual ventilation bags.

We set out to investigate whether any potentially harmful bacteria could be isolated from exposed preprepared endotracheal tubes. We found none. Therefore we conclude that it is safe to preprepare endotracheal tubes for rapid intubation in the resuscitation room provided that the exposed equipment is kept dry and that personnel minimise the handling of tubes.

We would like to thank Dr M Farrington and the microbiology laboratory of Addenbrooke's Hospital for assistance with this study.

1 Lowy FD, Carlisle PS, Adams A, Feiner C. The incidence of nosocomial pneumonia following urgent endotracheal intubation. Infect Control 1987;8:245-8.

2 Potgieter PD, Linton DM, Oliver S, Forder AA Nosocomial infections in a respiratory intensive care unit. Critical Care Medicine 1987:15:495-8.

3 Craven DE, Daschner FD. Nosocomial pneumonia in the intubated patient: role of gastric colonisation - a review. Eur $\mathcal{f}$ Clin Microbiol Infect Dis 1989;8:40-50.

4 Inglis TJ, Millar MR, Jones JG, Robinson DA. Tracheal tube biofilm as a source of bacterial colonisation of the tube biofilm as a source of bacterial colc

5 Cardinal P, Jessamine P, Carter-Snell C, Morrison S, Jones $G$. Contribution of water condensation in endotracheal tubes to contamination of the lungs. Chest 1993, tubes to

6 Weber DJ, Wilson MB, Rutala WA, Thomann CA. Manual ventilation bags as a source for bacterial colonisation of intubated patients. Am Rev Respir Dis 1990;142:892-4.

\section{BOOK REVIEWS}

Functional Anatomy and Physiology for Emergency Care in the Streets. By $\mathrm{J}$ Yamamoto and S Brada. (Pp 250; £17.00.) Boston: Little, Brown and Co, 1996. ISBN 0316967262.

How much anatomy and physiology does a paramedic need to know? This book has a difficult objective in striking a balance between a comprehensive textbook, and providing a framework of essential knowledge for the practising "emergency medical technician". The authors claim this is a textbook, but it is an introductory guide to these basic sciences - although generously flavoured with how the anatomy and physiology relates to illness or injury through its clinical correlations.

Educationally the book is very sound. The reader is involved in activities in the form of self assessment by patient management problems at the end of each chapter. Feedback on performance is provided by model management answers at the end of the book. A range of background knowledge is recognised and the authors provide a comprehensive vocabulary list at the end of each chapter, as well as an extensive glossary, to appeal to all levels of reader (individualisation). Relevance to practice in the streets is ensured by the frequent clinical correlations, which do give the reassuring feeling that the author is writing from personal experience. All the basic educational principles have therefore been followed ("FAIR" - feedback, activity, individualisation, relevance), and in addition the book is attractively set, with a large number of complementary simple line drawings and photographs.

However, there is a danger with oversimplification of being patronising, and the authors do on occasion cross this line. I found the explanation of the types of shock using the analogy of "Ecnalumba's power station and water system" an unnecessary affectation. Perhaps I have just failed to identify the pun or anagram. Specifically I did not find the sentence, "The last way the town of Ecnalumba's water system can fail is if there is a problem in the distribution of water to the shower" a useful description of the physiology of anaphylactic or neurogenic shock.

The book adopts a chatty, contemporary style highlighted by the opening quote in Chapter 1 - no not from Shakespeare but from a Steve Martin film. It has been written by American clinicians for the emergency medical technician market. There are no references from outside the United States in the recommended reading list and little recognition that the book may be read outside the USA (although adrenaline is in the index, cross referenced to epinephrine).

Overall I think the level of the book is pitched correctly for its intended audience. Paramedics in the United Kingdom may find it a helpful adjunct to their NHS Training Directorate manual. Readers of this journal will find little to excite them.

T J HODGETTS Military District Hospital Unit Frimley Park Camberley, Surrey

The Pre-Hospital Emergency Management Master. By T Hodgetts, I McNeil, and $M$ Cooke. (Pp 80; £29.95.) London: BMJ Publishing Group, 1995. ISBN 0 727909053.

The guidelines for reviewers were explicit "Avoid mentioning shelves departmental, library, etc - and whether the book should be on them." In the case of the Management Master this is, of course, obvious advice. For this is NOT a book to be kept in the library. Being constructed of Synteape, rip-proof paper, which in the words of the authors "ishard wearing for continual reuse and waterproof", the book has been compiled for use by emergency medical service personnel working outside the comforts and safety of the hospital.

I first came across the book a year ago when a portion of it had been developed as a record of events in a major incident and used as part of the major incident medical management and support course (MIMMS) developed by the Advanced Life Support Group of which the principal author, Tim Hodgetts, is a member. I was very impressed with the concept of logs and check lists and felt that this development filled a gap in the emergency care market. Since that time, the Management Master has been expanded considerably with additional check lists for medical emergencies, trauma (following the ATLS/PHTLS system), burns, and therapeutics. There is some extremely useful advice on scene management, scene assessment, and identification of hazards.

I have a slight unease at the effect that this new material will have on the overall success of the book. There are many pocket books now on the market with resuscitation algorithms and drug dosage listings (Parr and Crafts Resuscitation Key Data Quick Reference Guide being the obvious example as the main competitor to Hodgetts' book). Though I can see the Management Master being purchased for use in mobile ambulance control units and emergency support vehicles, I do not see it as the handbook of every individual practising prehospital care. Why, when the vast majority of information is in aid memoir form, have the authors chosen an A4 format - something pocket size would have been far more acceptable. Excellent though the concept is, I think that the market for this book is limited and I suspect that people who do purchase it end up donating it to the library or putting it on their departmental book shelf rather than keeping it to hand so that they have all the information together every time there is a prehospital emergency. 